\title{
Microporous $\mathrm{La}_{0.8} \mathrm{Sr}_{0.2} \mathrm{MnO}_{3}$ perovskite nanorods as efficient
}

\section{electrocatalysts for lithium-air battery}

Fanliang Lu ${ }^{\mathrm{a}}$, Yarong Wang ${ }^{\mathrm{a}}$, Chao Jin ${ }^{\mathrm{a}}$, Fan $\mathrm{Li}^{\mathrm{b}}$, Ruizhi Yang ${ }^{\mathrm{a} *}$, Fanglin Chen ${ }^{\mathrm{c}}$

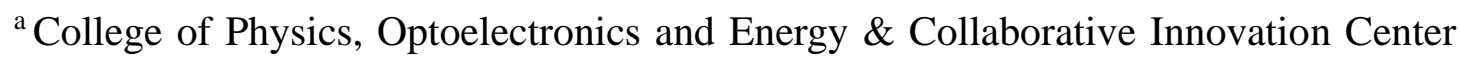
of Suzhou Nano Science and Technology, Soochow University, Suzhou 215006, China.

b College of Environmental and Energy Engineering, Beijing University of Technology, Beijing 100124, China

${ }^{c}$ Department of Mechanical Engineering, University of South Carolina, Columbia, SC 29208, USA

\begin{abstract}
Efficient electrocatalyst for oxygen reduction reaction (ORR) and oxygen evolution reaction (OER) is the most critical factor to influence the performance of lithium-air batteries. We present $\mathrm{La}_{0.8} \mathrm{Sr}_{0 .} \mathrm{MnO}_{3}$ (LSM) perovskite nanorods as high active electrocatalyst fabricated via a soft template method for lithium-air batteries. The as-prepared LSM nanorods are microporous with numerous defects and large surface area $\left(20.6 \mathrm{~m}^{2} \mathrm{~g}^{-1}\right)$, beneficial to the ORR and OER in the discharge and charge processes, respectively. Lithium-air batteries based on the microporous LSM nanorods electrocatalysts show enhanced electrochemical performances, including high first discharge specific capacity $\left(6890 \mathrm{mAh} \mathrm{g}^{-1}\right.$ (electrode) at $200 \mathrm{~mA} \mathrm{~g}$ ), low overpotential, good rate capability (up to $400 \mathrm{~mA} \mathrm{~g}^{-1}$ ), and cycle stability (only $1.1 \%$ voltage loss after 30 circles of specific capacity limit of $1000 \mathrm{mAh} \mathrm{g}^{-1}$ tested at 200 $\mathrm{mA} \mathrm{g}^{-1}$ ). The improved performance might be due to the synergistic effect of the unique microporous and one-dimensional structure and numerous defects of the prepared LSM catalyst.
\end{abstract}

* Corresponding author: Tel: +86 51265221519

E-mail: jinchao@suda.edu.cn (C. Jin); yangrz@suda.edu.cn (R. Yang) 


\section{KEYWORDS}

La0.8 $\mathrm{Sr}_{0.2} \mathrm{MnO}_{3}$ perovskite oxide; nanorods; micropore; catalyst; lithium-air battery

\section{Introduction}

Since a lithium-oxygen battery system based on nonaqueous electrolyte was presented by Abraham and Jiang in 1996 and the rechargeability of the system was explored by the Bruce group in 2006 [1, 2], rechargeable lithium-oxygen (or lithium-air) batteries have recently attracted worldwide attention and hold promise to replace traditional $\mathrm{Li}$-ion batteries (LIBs) in the areas of electric vehicles (EVs) and renewable energy storage due to their extremely high theoretical energy density (5200 Wh $\mathrm{kg}^{-1}$, including oxygen) which is comparable to that of gasoline and is 5-10 times higher than that of state-of-art LIBs [3-6]. However, in order to to enable lithium-air batteries for practical applications, there are numerous scientific challenges that need to be overcome, such as poor rate capability, low round-trip efficiency (due to terrible overpotentials for both oxygen reduction and evolution), instability of electrolyte, and especially short cycle life, et al.[7-9] In response, extensive studies are currently being conducted to address these challenges and improve electrochemical performances of rechargeable nonaqueous lithium-air batteries. The air electrode, especially efficient electrocatalyst for both oxygen reduction and oxygen evolution reactions is crucial.

Two main strategies have been explored to optimize the air electrode performances. One is to design new air electrode structure while the other is explore high efficiency bifunctional catalyst for both oxygen reduction reaction (ORR) and oxygen evolution reaction (OER) [10-20]. In the former case, the design of new air electrodes requires large specific surface area with enough effective active sites, which can greatly improve the ORR and OER kinetics and rate capacity. Meanwhile, enough void volumes and open frameworks in the architecture structures are necessary for accommodating the insoluble discharge products, and helpful to improve its discharge capacity and cycling performance. Various air electrode 
structures have been explored, such as conventional porous composite electrode [11], hierarchically porous functionalized graphene sheets [12], vertically aligned carbon nanotubes [13], et al. However, a general criterion has not been established yet. In the latter case, numerous studies have been reported, including platinum $(\mathrm{Pt})$ or palladium (Pd) based noble catalysts [14, 15], transition metal oxide catalysts [16-19], carbon materials, heterogeneous composite catalysts [20, 21], et al. An ideal bifunctional catalyst can effectively accelerate the ORR and OER processes, lower the overpotential and thus improve the performance of lithium-air batteries.

Among various types of electrocatalysts, perovskite oxides have also received much attention as efficient electrode materials due to its defective structure, relatively high electronic and ionic conductivity and excellent oxygen mobility [17, 22-25]. As one of the most frequently-used cathode materials in solid oxide fuel cells, $\mathrm{La}_{0} \mathrm{Sr}_{0.2} \mathrm{MnO}_{3}$ (LSM) perovskite oxide has demonstrated promising catalytic properties in lithium-air batteries with non-aqueous electrolyte $[17,26]$. For example, $\mathrm{Xu}$ et al have proposed porous $\mathrm{La}_{0 .}{ }_{25} \mathrm{Sr}_{0.25} \mathrm{MnO}_{3}$ nanotubes by electrospinning as electrocatalyst for lithium- $\mathrm{O}_{2}$ battery, which demonstrated ultrahigh charge and discharge capacities [17]. In our previous reports [23, 27], we have synthesized urchin-like and hollow spherical LSM perovskite oxides with high specific surface area, which exhibit better catalytic performances than regular LSM particles. Therefore, it is necessary and important to investigate the structural design of LSM in order to improve its catalytic performance. One-dimensional microporous/mesoporouse nanomaterials have been the subject of intensive research because of its unique advantages such as fast electron mobility due to no barrier to limit transmission, large specific surface area and continuous controllable pore size, $[28,29]$ et al. To the best of our knowledge, however, there has been no report using LSM nanorods electrocatalyst in the lithium-air batteries.

Herein, we report for the first time a rational and facile strategy for preparing LSM nanorods via a soft template method. The prepared LSM nanorods have microporous structure. We have characterized their catalytic activity for the ORR and OER, and applied them in the lithium-air batteries. The lithium-air batteries using the 
microporous LSM nanorods show an enhanced specific capacity, rate capability, and cycle stability.

\section{Experimental section}

All the reagents used in the experiment were of analytical grade and used without further purification.

\subsection{Synthesis of microporous LSM nanorods}

Microporous $\mathrm{La}_{0} \mathrm{Sr}_{0 .} \mathrm{MnO}_{3}$ (LSM) nanorods were prepared by a soft template method with cetrimonium bromide (CTAB) as a surfactant and template [30]. Stoichiometric amounts of $\mathrm{La}\left(\mathrm{NO}_{3}\right)_{3} \cdot 6 \mathrm{H}_{2} \mathrm{O}, \mathrm{Sr}\left(\mathrm{NO}_{3}\right)_{2}, \mathrm{Mn}\left(\mathrm{NO}_{3}\right)_{2}$ were dissolved in deionized water, and the concentration of total metal ions $\left(\mathrm{M}^{\mathrm{n}+}\right)$ was $0.5 \mathrm{~mol} \mathrm{\textrm {L } ^ { - 1 }}$. Then $50 \mathrm{mM}$ cetrimonium bromide (CTAB, $20 \mathrm{~mL})$ was added to the mixture $(70 \mathrm{~mL})$ and stirred for $0.5 \mathrm{~h}$. Meanwhile, supersaturated ammonium hydroxide $\left(\mathrm{NH}_{3} \cdot \mathrm{H}_{2} \mathrm{O}\right)$ was added to adjust the $\mathrm{pH}$ value to about 14.0. The mixed solution was then transferred into a $100 \mathrm{~mL}$ Teflon-lined stainless steel autoclave and heat-treated at $180{ }^{\circ} \mathrm{C}$ for $10 \mathrm{~h}$. After cooling to room temperature, the precipitates were separated, washed with deionized water and ethanol for several times then calcined at $700{ }^{\circ} \mathrm{C}$ for $4 \mathrm{~h}$ with a heating speed of $1{ }^{\circ} \mathrm{C} \min ^{-1}$ to obtain the final product.

LSM regular particles were also synthesized through a sol-gel method [31] for comparison. Stoichiometric amounts of $\mathrm{La}\left(\mathrm{NO}_{3}\right)_{3} \cdot 6 \mathrm{H}_{2} \mathrm{O}, \mathrm{Sr}\left(\mathrm{NO}_{3}\right)_{2}$, and $\mathrm{Mn}\left(\mathrm{NO}_{3}\right)_{2}$ were dissolved in deionized water, and the concentration of total metal ions $\left(\mathrm{M}^{\mathrm{n}+}\right)$ was $0.5 \mathrm{~mol} \mathrm{~L}{ }^{-1}$. Citric acid (CA) and ethylenediamine tetraacetic acid (EDTA) was then added to the mixture as a chelating agent and fuel, and the mole ratio of $\mathrm{M}^{\mathrm{n}+}: \mathrm{CA}$ : EDTA was controlled around $1: 1.5: 1 . \mathrm{NH}_{3} \cdot \mathrm{H}_{2} \mathrm{O}$ was added to adjust the $\mathrm{pH}$ value to about 8.0. Upon stirring while heating at $80{ }^{\circ} \mathrm{C}$ on a hot-plate for $24 \mathrm{~h}$, the solution transformed into a gel, which was then heated to $250{ }^{\circ} \mathrm{C}$ for $5 \mathrm{~h}$ in an oven to obtain a precursor powder. The precursor powder was pulverized and then calcined at $700{ }^{\circ} \mathrm{C}$ for $4 \mathrm{~h}$ in air.

\subsection{Characterizations}

The X-ray diffraction (XRD) data were obtained with a Bede D1 X-ray 
diffractometer (Bede Scientific Ltd., UK) equipped with $\mathrm{Cu}$ K $\alpha$ radiation from 20 to $80^{\circ}$ with a step of $0.02^{\circ}$ and a rate of $1.2^{\circ} \mathrm{min}^{-1}$. The morphology was characterized by a scanning electron microscope (SEM, Hitachi SU8010) and a transmission electron microscope (TEM; TecnaiG20 operating at $200 \mathrm{kV}$ ), respectively. The XPS spectra were analyzed by X-ray photoelectron spectroscopy (XPS, VG ESCALAB MKII). The specific surface areas and the pore size distributions of LSM nanorods are determined by nitrogen or carbon dioxide sorption isotherms for mesopores and micropores, respectively, which were performed on Automated Area and Pore Size Analyzers (Quadrasorb 2MP and Micromeritics ASAP 2020, separately). And all the pore size distributions and specific surface areas are evaluated with nonlocal density functional theory (NLDFT) method [32].

\subsection{Electrochemical measurements}

To evaluate electrochemical catalytic activities of LSM nanorods for the ORR and OER, the rotating ring-disk electrode (RRDE) technique using a Pine Electrochemical system (AFMSRX rotator, and AFCBP1 bipotentiostat) was performed in $0.1 \mathrm{M} \mathrm{KOH}$ solution. The clear procedures of electrode preparation and electrochemical tests were similar to our previous works [33-35] and given in supporting materials.

The electrochemical properties were carried out by assembling 2032 coin lithium-air batteries in a glove box filled with pure argon gas $\left(<1 \mathrm{ppm} \mathrm{H}_{2} \mathrm{O}\right.$ and $\left.\mathrm{O}_{2}\right)$, using a clean lithium pellet anode, a glass fibre separator (GF/C, Whatman), an electrolyte containing $1 \mathrm{M}$ LiTFSI (bis(trifluoromethane)sulfonimide lithium salt) in TEGDME (tetraethylene glycol dimethyl ether), an oxygen cathode. The oxygen cathodes were prepared by spraying homogenous ink composed of the mixture of 15 wt.\% LSM nanorods, 75 wt.\% acetylene black and $10 \mathrm{wt} . \%$ polyvinylidene fluoride (PVDF) on carbon paper current collector. $0.5 \mathrm{mg}$ acetylene black and electrocatalyst were loaded on carbon paper $(\Phi 12 \mathrm{~mm})$. The galvanostatic discharge-charge tests were conducted within a voltage window of $2.2-4.4 \mathrm{~V}$ (vs. $\mathrm{Li} / \mathrm{Li}^{+}$) with a multichannel battery testing system (LAND CT 2001A) in a testing glove box filled with a dry gas mixture composed of 80 vol.\% pure $\operatorname{Ar}(99.999 \%)$ and 20 vol.\% pure 
$\mathrm{O}_{2}(99.999 \%)$. The capacity was calculated based on the sum mass of acetylene black and electrocatalyst. Cyclic voltammetry (CV) experiments were carried out with $\mathrm{CHI}$ 604B electrochemical workstation from 4.5 to $2.0 \mathrm{~V}$ at a scan rate $0.2 \mathrm{mV} \mathrm{s}^{-1}$.

For comparison, lithium-air batteries with pure acetylene black and regular LSM particles as cathode catalyst were also assembled and tested with the same procedure, respectively.

\section{Results and discussion}

\subsection{Structure and morphology characterizations}

The synthesis of microporous LSM nanorods involves interfacial self-assembly process with $\mathrm{CTAB}$ as soft template followed by hydrothermal and calcination treatment, as schematically shown in Figure 1(a). The first step is to form CTAB rod-like micelles. Critical micelle concentration (CMC) of CTAB has been reported to be $0.9-1.0 \mathrm{mM}$ [36]. Above the CMC, a transition from spherical micelles to rod-like micelles occurred, and the size of the micelles increased with the increase of CTAB concentration, eventually resulting in long, flexible wormlike micelles [37]. In our system, with CTAB concentration of around $50 \mathrm{mM}$, CTAB could easily form rod-like micelles. CTAB is a cationic surfactant, and it would easily ionize to form $\mathrm{CAT}^{+}$in the aqueous solution, and $\mathrm{CAT}^{+}$would directionally arrange on the surface of rod-like micelles. With addition of metal nitrates and supersaturated ammonium hydroxide, interfacial self-assembly process was performed. $\mathrm{CAT}^{+}-\mathrm{OH}^{-}$bond was firstly formed, then metal hydroxyl precipitate $\left(\mathrm{Ln}(\mathrm{OH})_{\mathrm{n}}\right)$ was obtained along rod-like micelles because of electrostatic force between $\mathrm{Ln}^{\mathrm{n}+}$ and $\mathrm{OH}^{-}$. When hydrothermal temperature is over $160{ }^{\circ} \mathrm{C}, \mathrm{CTAB}$ micelles will be destroyed [38], and there is only single CTAB adsorbing $\mathrm{Ln}(\mathrm{OH})_{\mathrm{n}}$ core around, which plays as crystal growth agent and controls the anisotropy of crystal growth before eventual precursor formation of $\mathrm{Ln}(\mathrm{OH})_{\mathrm{n}}$ nanorod. During the calcinating process, water molecule continually formed and removed in the form of steam, resulting in the formation of micropore. Microporous LSM nanorods were finally obtained after calcinating at $700{ }^{\circ} \mathrm{C}$ for $4 \mathrm{~h}$ in air. 
Microporous LSM nanorods calcined at different temperature were characterized by $\mathrm{X}$-ray diffraction (XRD) analysis, as presented in Figure 1(b). Compared with the standard PDF card (PDF\#40-1100), all the characteristic peaks can be well indexed as a perovskite phase with a rhombohedral structure, except that a trace small peak around 36 degrees correspond to $\mathrm{La}(\mathrm{OH})_{3}$ and/or $\mathrm{La}_{2} \mathrm{O}_{3}$. No other peaks can be observed, indicating high phase purity of the synthesized sample. The detailed surface composition and oxidation state of the microporous LSM nanorods were analyzed by XPS as shown in Figure S1. The full survey indicates the presence of La 3d, Sr 3d, Mn 2p and O 1s in Figure S1(a). With a Gaussian fitting method, the high-resolution Mn 2p spectrum was best fitted with two spin-orbital doublets, corresponding to $\mathrm{Mn}^{3+}$ and $\mathrm{Mn}^{4+}$ (Figure $\mathrm{S} 1(\mathrm{~b})$ ). The high-resolution $\mathrm{O}$ 1s spectrum contains four oxygen contributions denoted as O1, O2, O3, and O4 in Figure S1(c) [39]. Component $\mathrm{O} 1$ represents metal-oxygen bonds. The component $\mathrm{O} 2$ is typical of oxygen in hydroxyl groups, which may be due to the oxygen atoms of surface hydroxyl groups. Note that the relative intensity and peak areas of $\mathrm{O} 2$ corresponding to the adsorbed oxygen species are obviously higher than that of O1, which is benefitial to improving the catalytic activities for the ORR and OER [40]. The resolved O3 component is associated with oxygen in low coordination at the surface, which is common for nanoparticles. The $\mathrm{O} 4$ contribution corresponds to multiplicity of physisorbed and chemisorbed water on or near the surface.

Figure 2(a) shows the nitrogen adsorption and desorption isotherm and the pore-size distribution of the prepared LSM nanorods. It can be observed that a similar Type I isotherm was obtained, and there are no mesopores according to the pore-size distribution (inset in Figure 2(a)). Since $\mathrm{CO}_{2}$ adsorption isotherm could give more reliable quantitative assessment in the range of micropores, $\mathrm{CO}_{2}$ was also used as the adsorptive instead of $\mathrm{N}_{2}$ for the measurement of the micropores. The $\mathrm{CO}_{2}$ adsorption and desorption isotherm and the pore-size distribution are shown in Figure 2(b). It can be seen that the prepared LSM nanorods display microporous features with Type I isotherm, resulting from the higher initial leap at low pressure [41]. The $\mathrm{CO}_{2}$ adsorption and desorption isotherm reveals a specific surface area of $20.6 \mathrm{~m}^{2} \mathrm{~g}^{-1}$, and 
pore volume of $0.093 \mathrm{~cm}^{3} \mathrm{~g}^{-1}$ with an average pore size of $1.0 \mathrm{~nm}$, which is particularly beneficial to provide more effective catalytic active sites.

The detailed morphology and structural features of the prepared samples were further characterized by SEM and TEM. Figure 3(a) shows SEM image of microporous LSM nanorods after being calcined at $700{ }^{\circ} \mathrm{C}$. It can be observed that well dispersed LSM nanorods with an average diameter of $25 \mathrm{~nm}$ and length of 150 $\mathrm{nm}$ have been achieved. Moreover, we have also evaluated effects of CTAB concentrations and calcination temperatures on the morphology of microporous LSM nanorod precursors and final products, as shown in Figure S2 and Figure S3, respectively. From Figure S2, it can be seen that the length of microporous LSM nanorod precursors increased with CTAB concentration from $10 \mathrm{mM}$ to $50 \mathrm{mM}$, however, there appeared aggregation when excess CTAB is used. Although nanorods structure has been well preserved after calcinations as displayed in Figure S3, there exhibited serious agglomeration after being calcined at $800{ }^{\circ} \mathrm{C}$. Figure 3(b) shows TEM image of the microporous LSM nanorod. Well dispersed LSM nanorod with a length of $200 \mathrm{~nm}$ is clearly observed, which is in agreement with the SEM result. The HRTEM image of the microporous LSM nanorods shows an interplaner spacing of $0.196 \mathrm{~nm}$, corresponding to the (220) plane of the $\mathrm{La}_{0.8} \mathrm{Sr}_{0.2} \mathrm{MnO}_{3}$ (PDF\#40-1100), as shown in Figure 3(c). Remarkably, after a Fast Fourier Transform (FFT) treatment of the HRTEM image (Figure 3(c2), numerous line defects corresponding to marked regions in Figure 3(c) can be clearly observed, as shown in Figure 3(c1) and (c3). The corresponding selected area electron diffraction (SAED) pattern (Figure 3(d)) can be indexed as along the beam direction of (220). Moreover, the dot splits (marked with red arrows) confirm the presence of defects. These defects can facilitate binding intermediate $\mathrm{O}_{2}{ }^{2-}$ to the catalyst accompanied by the cleavage of $\mathrm{Li}^{+}$from $\mathrm{Li}_{2} \mathrm{O}_{2}$ [42] .

This microporous LSM nanorods are expected to be an ideal electrocatalyst for the ORR and OER because of the following advantages: 1) the one-dimensional nanorods structure could facilitate the electron transport due to shorter conducting path; 2) the microporous morphology could provide more catalytic active sites; 3) the presence of numerous line defects is beneficial to improving the catalytic activities. 
All these favorable advantages would benefit the electrochemical performance of lithium-air batteries.

\subsection{Electrocatalytic activities characterizations}

Before assembling and testing lithium-air batteries, electrochemical catalytic activities of microporous LSM nanorods for the ORR and OER were firstly evaluated using a rotating ring-disk electrode (RRDE) technique in $\mathrm{O}_{2}$ saturated $0.1 \mathrm{M} \mathrm{KOH}$ solution. For comparison, LSM regular particles, commercial Pt/C (20 wt.\% Pt) and pure carbon electrocatalysts were also measured with the same testing conditions, respectively. The disk and ring currents were measured at $2500 \mathrm{rpm}$ and normalized by the geometric surface area. According to the results shown in Figure 4(a), the onset potential, half-wave potential and diffusion limiting current density of these three catalysts were displayed in Table 1. The ORR activity increases as the following: pure $\mathrm{C}<\mathrm{LSM}$ particle $<\mathrm{LSM}$ nanorod $<\mathrm{Pt} / \mathrm{C}$, as shown in Table 1 . The diffusion limiting current density of $-6.30 \mathrm{~mA} \mathrm{~cm}{ }^{-2}$ for the LSM nanorod was obtained, which is close to that of $\mathrm{Pt} / \mathrm{C}\left(-6.60 \mathrm{~mA} \mathrm{~cm}{ }^{-2}\right)$, and a half-wave potential difference of about 130 $\mathrm{mV}$ exists between LSM nanorod and Pt/C. Considering that our tested diffusion limiting current density and half-wave potential of the $\mathrm{Pt} / \mathrm{C}$ are in good agreement with the values of Pt/C (20 wt.\% Pt) reported elsewhere [43, 44], we can conclude that microporous LSM nanorods are more active than regular the LSM particles and comparable to the activity of $\mathrm{Pt} / \mathrm{C}$.

To better evaluate the oxygen reduction kinetic parameters of the microporous LSM nanorods catalyst during the ORR process, the RRDE measurements were carried out in a cathodic sweep with $10 \mathrm{mV} \mathrm{s}^{-1}$ at various rotation speeds $(\omega)$ from 400 to $2500 \mathrm{rpm}$. Both ring current density $\left(i_{r}\right)$ and disk current density $\left(i_{d}\right)$ were collected and shown in Figure S4(a). It can be seen that the diffusion limiting current densities increased as the rotation speed increases from 400 to $2500 \mathrm{rpm}$. Higher rotation speeds lead to faster oxygen flux to electrode surface and consequently larger currents. According to $i_{r}$ and $i_{d}$ curves, the transferred electron number $(n)$ and the contents of peroxide $\mathrm{HO}_{2}^{-}$during the ORR were also calculated and displayed in Figure S4(b) and (c), respectively. The $n$ values are $3.7 \sim 4.0$ and the measured $\mathrm{HO}_{2}{ }^{-}$ 
yields are below $15.0 \%$ over the measured potential range, indicating a $4 \mathrm{e}^{-}$pathway for the microporous LSM nanorods catalyst during the ORR process.

Anodic linear scanning voltammograms for the OER on these four catalysts coated rotating-disk electrode in $\mathrm{O}_{2}$ saturated $0.1 \mathrm{M} \mathrm{KOH}$ solution at $1600 \mathrm{rpm}$ were also carried out and compared in Figure 4(b). Although LSM is the most active for ORR in previously reported perovskite oxides, but has low intrinsic activity for OER [45-47]. From Figure 4(b), it can be clearly observed that microporous LSM nanorod demonstrated lower activity for OER than that of $\mathrm{Pt} / \mathrm{C}$, however, an enhanced activity was obtained compared with that of LSM particle and pure C.

The stabilities of microporous LSM nanorods and commercial Pt/C catalysts for the ORR and OER were further examined with the chronoamperometric method in $\mathrm{O}_{2}-$ saturated $0.1 \mathrm{M} \mathrm{KOH}$ at $1600 \mathrm{rpm}$. The $\mathrm{ORR}$ potential was selected to be $-0.3 \mathrm{~V}$ vs. $\mathrm{Ag} / \mathrm{AgCl}$, while the OER potential was selected to be $0.8 \mathrm{~V}$ vs. $\mathrm{Ag} / \mathrm{AgCl}$. The results obtained are shown in Figure S5. Impressively, microporous LSM nanorods present little attenuation after over $40,000 \mathrm{~s}$ of continuous operation.

\subsection{Lithium-air battery performances}

The electrocatalytic activities of the microporous LSM nanorods catalyst are then examined in lithium-air batteries. A conventional LSM particle catalyst and pure acetylene black electrode are also employed for comparison. We utilized cyclic voltammetry $(\mathrm{CV})$ to explore the ORR and OER catalytic activity of the microporous LSM nanorods in the LiTFSI-TEGDME electrolyte from 4.5 to $2.0 \mathrm{~V}$ (Figure 5(a)). Compared with the LSM particle based and pure acetylene black based electrodes, the microporous LSM nanorod based electrode exhibits a higher ORR onset potential $(2.86 \mathrm{~V})$ and ORR/OER peak current. The enhanced ORR/OER kinetics is beneficial to improve the energy output, the recharging characteristic, and the round-trip efficiency of the lithium-air battery.

The first discharge/charge profiles at a discharge and charge current density of 200 $\mathrm{mA} \mathrm{g}^{-1}$ of lithium-air batteries with the three different air electrode catalysts are displayed in Figure 5(b). It can be clearly seen that the first discharge capacity of the microporous LSM nanorods based lithium-air battery is $6890 \mathrm{mAh} \mathrm{g}^{-1}$ (electrode), while 
that of regular LSM particles and pure acetylene black based lithium-air batteries are 3925 and $1937 \mathrm{mAh} \mathrm{g}^{-1}$ (electrode), respectively. Interestingly, it can be found that the discharge and especially the charge voltage of lithium-air batteries can be improved with the help of the microporous LSM nanorods catalyst, which would consequently enhance the round-trip efficiency. Although the discharge voltage of lithium-air batteries with the microporous LSM nanorods based electrode is higher than that of regular LSM particles based electrode by about $70 \mathrm{mV}$ and pure acetylene black electrode by about $140 \mathrm{mV}$, its averaged charge voltage is much lower than that of the regular LSM particles based and pure acetylene black based lithium-air batteries. It should be noted that these differences in discharge and charge voltages might be due to the different catalytic activities of these three electrodes, and the microporous LSM nanorods based electrode shows better catalytic activity.

Figure 5(c) presents the discharge and charge profiles of the microporous LSM nanorods based lithium-air batteries in the first cycle at different current densities of $100 \mathrm{~mA} \mathrm{~g}^{-1}, 200 \mathrm{~mA} \mathrm{~g}^{-1}$ and $400 \mathrm{~mA} \mathrm{~g}^{-1}$ to study rate capability. When the current density decreases from 400 to $100 \mathrm{~mA} \mathrm{~g}^{-1}$, the discharge capacity increases from 4763 to $8890 \mathrm{mAh} \mathrm{g}^{-1}$ (electrode) and the voltage gap between charge and discharge plateaus declines, showing a good rate capability. Discharge and charge stability is one of the most critical aspects of nonaqueous lithium-air batteries, however, it is typically difficult to realize due to the accumulation of the discharge product, and the instability of the electrolyte. It has been reported that improved cycle performance can be achieved by using optimized catalysts. Under the circumstance of deep discharge and charge depth at $200 \mathrm{~mA} \mathrm{~g}^{-1}$, the microporous LSM nanorods based lithium-air battery shows a stable cycle performance for five cycles, as shown in Figure 5(d). After five cycles of fully discharge and charge, the specific capacities can maintain over 4000 $\mathrm{mAh} \mathrm{g}^{-1}$ (electrode), with a retention of $57 \%$. As a comparison, a fully discharge and charge cyclic experiment of lithium-air battery based on regular LSM particle electrode was also carried out, and the result was shown in Figure S6. It can be seen that the specific capacity kept only $31 \%$ after five cycles. Furthermore, columbic efficiency of the microporous LSM nanorods based lithium-air battery was also 
calculated and displayed in Figure 5(e) according to the discharge and charge data as shown in Figure 5(d). It can be observed that the charge capacity is quite close to the discharge capacity and the columbic efficiency is over $80 \%$, suggesting a good charging efficiency. To further confirm the stability of the microporous LSM nanorods based lithium-air battery, specific capacity limit of $1000 \mathrm{mAh} \mathrm{g}^{-1}$ test was performed at $200 \mathrm{~mA} \mathrm{~g}^{-1}$ after five cycles of fully discharged/charged measurements. As shown in Figure 5(f), the terminal discharge voltage is over $2.67 \mathrm{~V}$ after 30 cycles with $1.1 \%$ voltage loss, implying the good stability of the microporous LSM nanorods catalyst.

Figure 6 shows SEM images of the microporous LSM nanorods based electrode during the discharge and charge process. The lithium-air battery is discharged and charged at $200 \mathrm{~mA} \mathrm{~g}^{-1}$ from open circuit voltage (OCV) to $2.2 \mathrm{~V}$ and $4.4 \mathrm{~V}$, respectively. Before discharge, the LSM nanorods and acetylene black are loosely dispersed in the initial electrode (Figure 6(a)). It is found that, after the 1st discharge, the surface of the electrode is almost fully covered by a film as shown in Figure 6(b), which is mainly composed of some insoluble species such as $\mathrm{Li}_{2} \mathrm{O}_{2}$ particles. In nonaqueous electrolyte based $\mathrm{Li}$-air batteries, $\mathrm{Li}_{2} \mathrm{O}_{2}$ is confirmed as the main discharged product during the initial cycle. [3, 16, 48-50]. However, the open framework of the electrode can still be well maintained, ensuring to get uniform oxygen and electrolyte distribution around the discharge products, which can thus promote the decomposition of the products to ensure recovery of the electrode porosity during the charge process and result in enhancement of rechargeability. After the 1st charge, the porous structure and nanoparticulated morphology are essentially recovered (Figure 6(c)). These results suggest the superior activity of the microporous LSM nanorods in catalysing the oxidation of $\mathrm{Li}_{2} \mathrm{O}_{2}$ during the charging process.

\section{Conclusion}

In summary, microporous LSM nanorods have been successfully fabricated through a soft template method followed by a calcination process. When evaluated as electrocatalyst for the ORR and OER in alkaline solution, the microporous LSM nanorods show enhanced catalytic activities compared with the regular LSM particle, 
and demonstrate better stabilities than that of commercial Pt/C electrocatalyst. When employed as electrocatalyst in a lithium-air battery, the high catalytic activity of the microporous LSM nanorods enables the lithium-air battery with a high specific capacity, superior rate capability, and good cycle stability. The results presented here indicate that the microporous LSM nanorod is a very promising and efficient catalyst for aprotic lithium-air battery.

\section{Acknowledgements:}

The project was supported by National Natural Science Foundation of China (51272167, 21206101), Natural Science Foundation of Jiangsu Province, China (BK20141199), Natural Science Foundation of the Higher Education Institutions of Jiangsu Province, China (12KJB430010, 14KJB480005), and the U.S. National Science Foundation (DMR-1210792).

\section{References}

[1] K.M. Abraham, Z. Jiang, J. Electrochem. Soc. 143 (1996) 1-5.

[2] T. Ogasawara, A. Debart, M. Holzapfel, P. Novak, P.G. Bruce, J. Am. Chem. Soc. 128 (2006) 1390-1393.

[3] P.G. Bruce, S.A. Freunberger, J.M. Tarascon, Nat. Mater. 11 (2012) 19-26.

[4] Z.Q. Peng, S.A. Freunberger, P.G. Bruce, Science 337 (2012) 563-566.

[5] R. Black, B. Adams, L.F. Nazar, Adv. Energy Mater. 2 (2012) 801-815.

[6] C.O. Laoire, S. Mukerjee, K.M. Abraham, E.J. Plichta, M.A. Hendrickson, J. Phys. Chem. C 114 (2010) 9178-9186.

[7] M. Park, H. Sun, H. Lee, J. Lee, J. Cho, Adv. Energy Mater. 2 (2012) 780-800.

[8] G. Girishkumar, B. McCloskey, A.C. Luntz, S. Swanson, W. Wilcke, J. Phys. Chem. Lett. 1 (2010) 2193-2203

[9] M.M. O. Thotiyl, S.A. Freunberger, Z.Q. Peng, P.G. Bruce, J. Am. Chem. Soc. 135 (2013) 494-500.

[10] J.J. Wang, Y.L. Li, X.L. Sun, Nano Energy 2 (2013) 443-467.

[11] Y.C. Lu, D.G. Kwabi, K.P.C. Yao, J.R. Harding, J. Zhou, L. Zuin, S.H. Yang, 
Energy Environ. Sci. 4 (2011) 2999-3007.

[12] J. Xiao, D.H. Mei, X.L. Li, W.Xu, D.Y. Wang, G.L. Graff, W.D. Bennett, J. Liu, J.G. Zhang, Nano Lett. 11 (2011) 5071-5078.

[13] J. H. Lee, R. Black, G. Popov, E. Pomerantseva, F. Nan, G.A. Botton, L.F. Nazar, Energy Environ. Sci. 5 (2012) 9558-9565.

[14] Y.C. Lu, S.H. Yang, J. Am. Chem. Soc. 133 (2011) 19048-19051.

[15] J.J. Xu, Z.L Wang, D. Xu, X.B. Zhang, Nat. Commun. 4 (2013) 2438-2447.

[16] X.P. Han, F.Y. Cheng, J. Chen, Chem. Commun. 50 (2014) 1497-1441.

[17] J.J. Xu, D. Xu, Z.L Wang, H.G. Wang, L.L Zhang, X. B. Zhang, Angew. Chem. Int. Ed. 52 (2013) 3887-3890.

[18] L.J. Li, A. Manthiram, Nano Energy 9 (2014) 94-100.

[19] F.L. Lu, X.C. Cao, Y.R. Wang, C. Jin, M. Shen, R.Z. Yang, RSC Adv. 4 (2014) 40373-40376.

[20] A. Kraytsberg, Y. Ein-Eli, Nano Energy 2 (2013) 468-480.

[21] J. Lu, Y. Lei, K.C. Lau, X.Y. Luo, P. Du, D.A. El-Hady, Y.K. Sun, L.A. Curtiss, K. Amine, Nat. Commun. 4 (2013) 2383-2387.

[22] J. Suntivich, J.B. Goodenough, S.H. Yang, Science 334 (2011) 1183-1186.

[23] C. Jin, X.C. Cao, C. Zhang, R.Z. Yang, J. Power Sources 241 (2013) 225-230.

[24] Y. L. Zhao, L. Xu, L. Q. Mai, X. Liu, PNAS 109 (2012) 19569-19574.

[25] C. Jin, X. C. Cao, F. L. Lu, Z. R. Yang, R. Z. Yang, Int. J. Hydrogen Energy 38 (2013) 10389-10393.

[26] Z. H. Fu, A.H. Yu, J. Solid State Electrochem. 16 (2012) 1447-1451.

[27] F.L Lu, J. Sui, J.M. Su, C. Jin, R.Z. Yang, J. Power Sources 271 (2014) 55-59.

[28] B.P. Nabar, Z. Celik-Butler, D.P. Butler, Nano Energy 10 (2014) 71-82.

[29] J.L. Shui, F. Du, C.M. Xue, Q. Li, L.M. Dai, ACS NANO 8 (2014) 3015-3022.

[30] Y. Lu, Y. Yang, A. Sellinger, Nature 410 (2001) 913-917.

[31] C. Jin, Z.B. Yang, F.L. Chen, Electrochem. Commun. 14 (2012) 75-77

[32] M. Thommes, Chemie Ingenieur Technik 82 (2010) 1059-1073.

[33] C. Jin, X.C. Cao, R.Z. Yang, ACS Appl. Mater. Interfaces 6 (2014) 847-853

[34] C. Jin, F.L. Lu, Z.R. Yang, R.Z. Yang, J. Mater. Chem. A 1 (2013) 12170 -12177 
[35] Y.R. Wang, Z.B. Yang, C. Jin, J. Wu, R.Z. Yang, RSC Adv. 5 (2015) 974-980.

[36] M. Delsannti, J.P. Munch, J. Colloid Interface Sci. 157 (1993) 285-290.

[37] S.H. Han, W.G. Hou, J. Xu, J.F. Hu, D.Q. Li, Mater. Lett. 57 (2003) 4520.

[38] J Wu, H. Zhang, X. Ma, Mater. Lett. 60 (2006) 3895-3898.

[39] D. Zhao, Y. Xiao, X. Wang, Q. Gao, M.H. Cao, Nano Energy 7 (2014) 124-133.

[40] F.Y. Cheng, J. Shen, B. Peng, Z.L. Tao, J. Chen, Nat. Chem. 3 (2011) 79-84.

[41] L. Zhao, L.Z. Fan, M.Q. Zhou, H. Guan, S. Qiao, M. Antonietti, M.M. Titirici, Adv. Mater. 22 (2010) 5202-5203.

[42] S. H. Oh, R. Black, L. F. Nazar, Nat. Chem. 4 (2012) 1004-1010

[43] J. Wu, Z.R. Yang, X.W. Li, Q.J. Sun, C. Jin, P. Strasser, R.Z. Yang, J. Mater. Chem. A 1 (2013) 9889-9894.

[44] J.B. Goodenough, A. Manthiram, J. Solid State Chem. 88 (1990) 115-120.

[45] J. Suntivich, H.A. Gasteiger, N. Yabuuchi, H. Nakanishi, J.B. Goodenough, S.H. Yang, Nat. Chem. 3 (2011) 546-550.

[46] K.A. Stoerzinger, M. Risch, J. Suntivich, W.M. Lü, J. Zhou, M.D. Biegalski, H.M. Christen, T. Venkatesan, S.H. Yang, Energy Environ. Sci. 6 (2013) 1582-1590.

[47] M. Risch, K.A. Stoerzinger, S. Maruyama, W.T. Hong, I. Takeuchi, S.H. Yang, J. Am. Chem. Soc. 136 (2014) 5229-5232

[48] Y.M. Cui, Z.Y. Wen, X. Liang, Y. Lu, J. Jin, M.F. Wu, X.W. Wu, Energy Environ. Sci. 5 (2012) 7893-7897.

[49] B.D. Adams, C. Radtke, R. Black, M.L. Trudeau, K. Zaghib, L.F. Nazar, Energy Environ. Sci. 6 (2013) 1772-1778.

[50] Y.Y. Shao, F. Ding, J. Xiao, J. Zhang, W. Xu, S. Park, J.G. Zhang, Y. Wang, J. Liu, Adv. Funct. Mater. 1 (2012) 16-20. 


\section{Figure and table captions:}

Figure 1, (a) Schematic illustration of microporous LSM nanorods preparation process; (b) XRD patterns of the as-prepared microporous LSM nanorods calcined at $700{ }^{\circ} \mathrm{C}$ and $800{ }^{\circ} \mathrm{C}$, respectively.

Figure 2, (a) $\mathrm{N}_{2}$ adsorption-desorption isotherm loop and pore distribution plot (inset) of microporous LSM nanorods; (b) $\mathrm{CO}_{2}$ adsorption-desorption isotherm loop and pore distribution plot (inset) of microporous LSM nanorods.

Figure 3, (a) SEM and (b) TEM images of microporous LSM nanorods calcined at $700{ }^{\circ} \mathrm{C}$; (c) High-resolution TEM image and the corresponding FFT patterns; (d) The corresponding selected area electron diffraction (SAED) patterns of microporous LSM nanorods.

Figure 4, (a) Linear sweeping voltammograms (LSVs) on the rotating ring-disk electrode for the as-prepared LSM nanorods, LSM particles, pure C and commercial $\mathrm{Pt} / \mathrm{C}$ in $\mathrm{O}_{2}$ saturated $0.1 \mathrm{M} \mathrm{KOH}$ solution at $2500 \mathrm{rpm}$; (b) Comparisons of catalytic activities for the $\mathrm{OER}$ in $\mathrm{O}_{2}$ saturated $0.1 \mathrm{M} \mathrm{KOH}$ solution at $1600 \mathrm{rpm}$.

Figure 5, (a) CV curves of microporous LSM nanorods, LSM particles, and pure acetylene black based lithium-air batteries at a scan rate of $0.2 \mathrm{mV} \mathrm{s}^{-1}$, respectively; (b) Comparisons of first discharge-charge curves of different lithium-air batteries at $200 \mathrm{~mA} \mathrm{~g}^{-1}$; (c) Rate capacities of lithium-air batteries based on the microporous LSM nanorods catalyst under different current densities; (d) Typical discharge-charge voltage profiles and (e) cycling performances of the initial 5 cycles of microporous LSM nanorods catalyst based lithium air batteries at $200 \mathrm{~mA} \mathrm{~g}^{-1}$ between 2.0 and 4.4 V; (f) Cycling stability of microporous LSM nanorods based lithium-air battery under specific capacity limit of $1000 \mathrm{mAh} \mathrm{g}^{-1}$ at $200 \mathrm{~mA} \mathrm{~g}^{-1}$.

Figure 6, SEM images of microporous LSM nanorods catalyst based electrode: (a) pristine, (b) after $1^{\text {st }}$ discharge and (c) after $1^{\text {st }}$ charge.

Table 1, Summary of the ORR catalytic characteristics of LSM nanorod, LSM particle, $\mathrm{Pt} / \mathrm{C}$ and pure $\mathrm{C}$. 
(a) CTA $^{+}$micelle
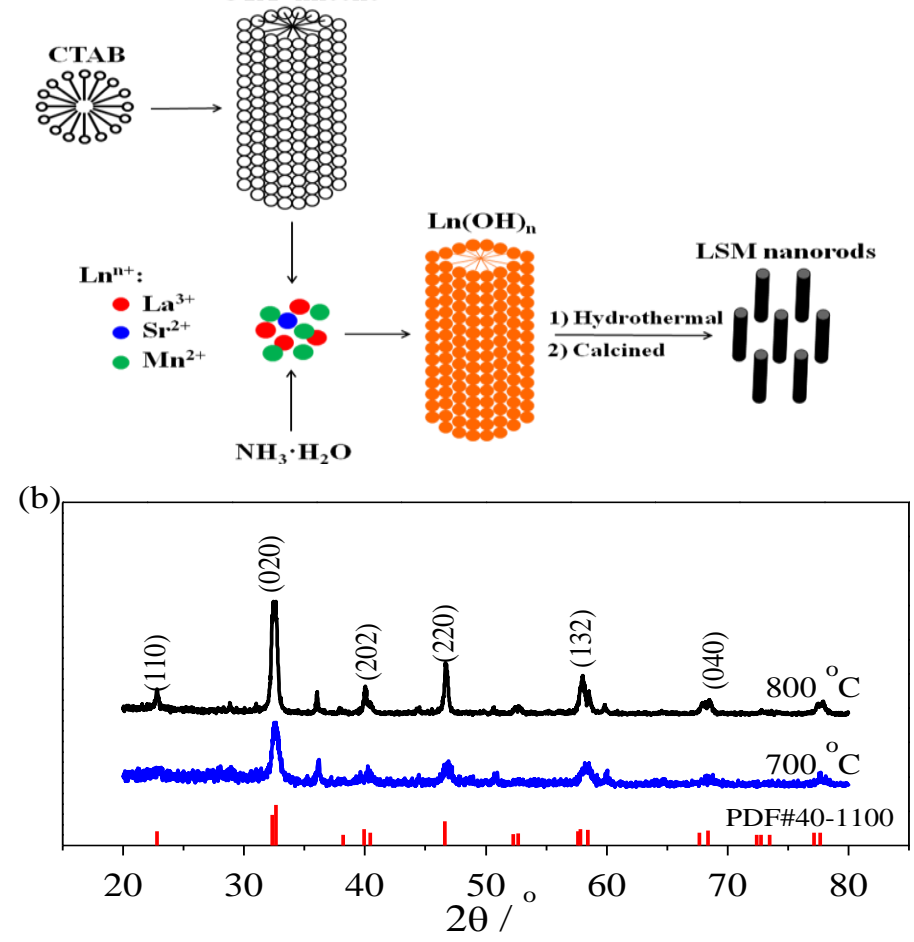

Figure 1, 

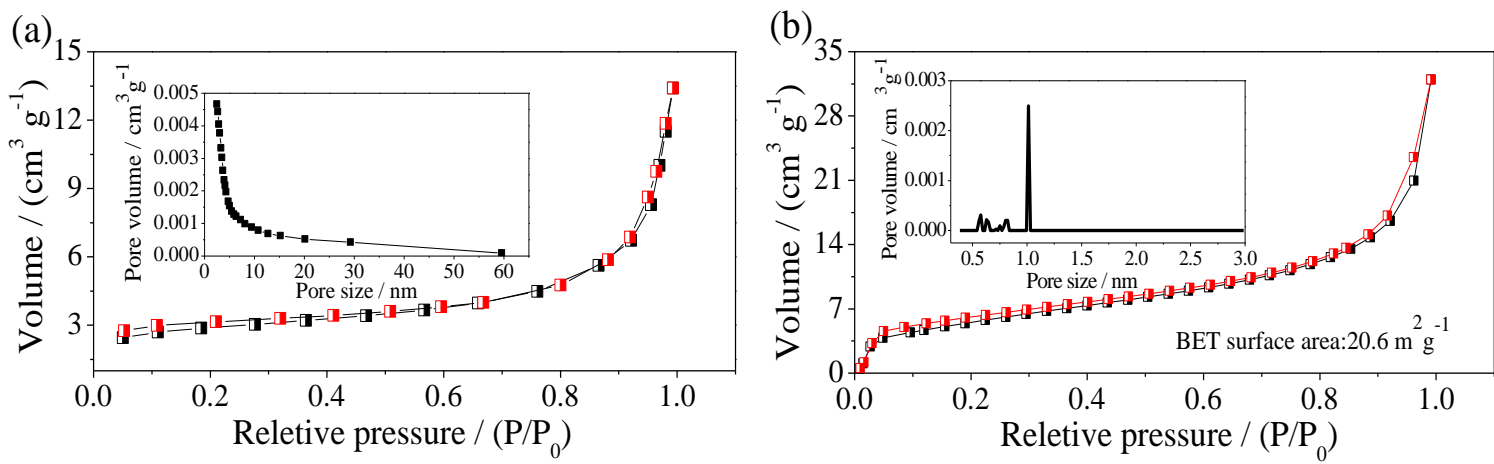

Figure 2 

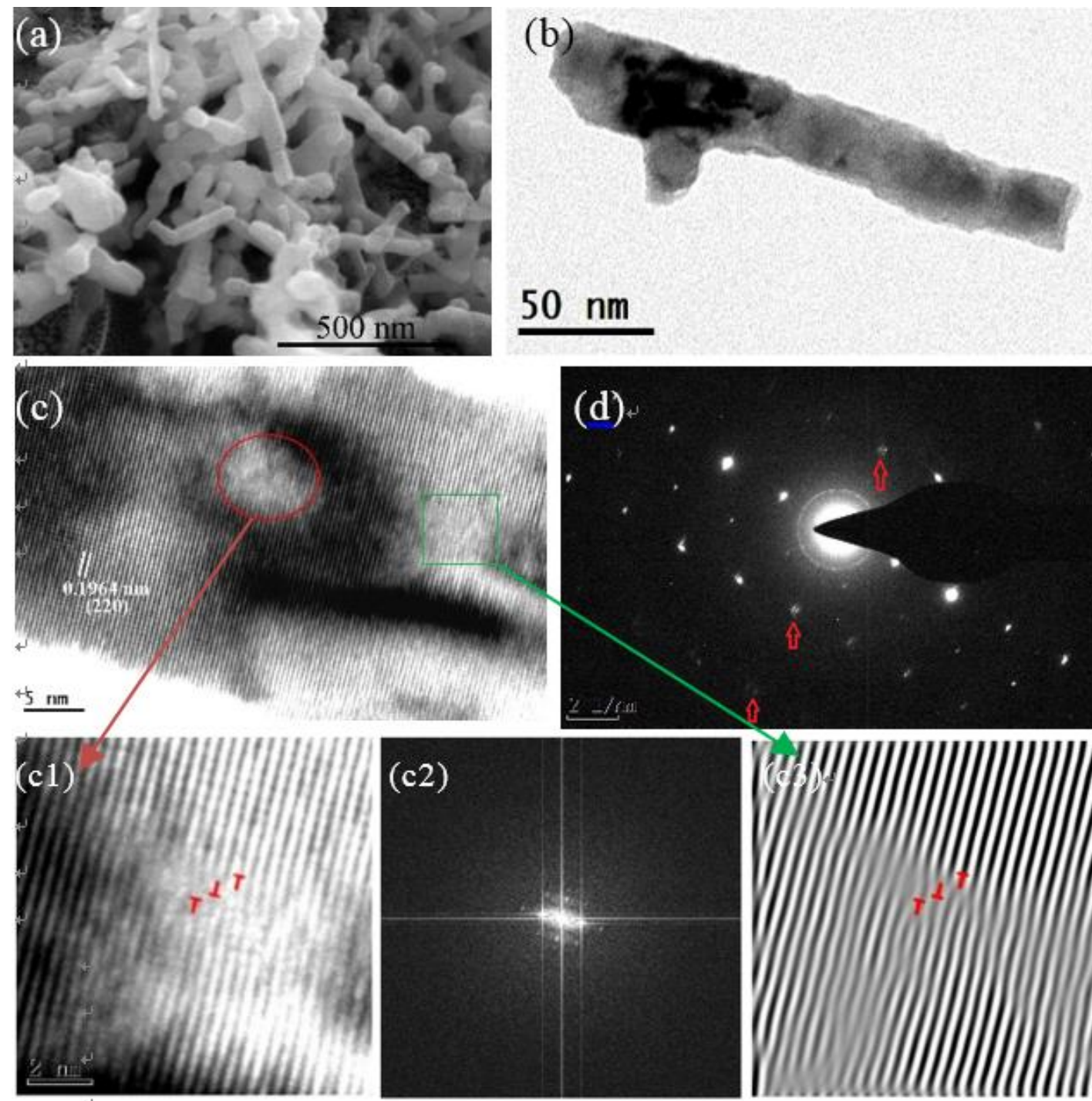

$50 \mathrm{~nm}$
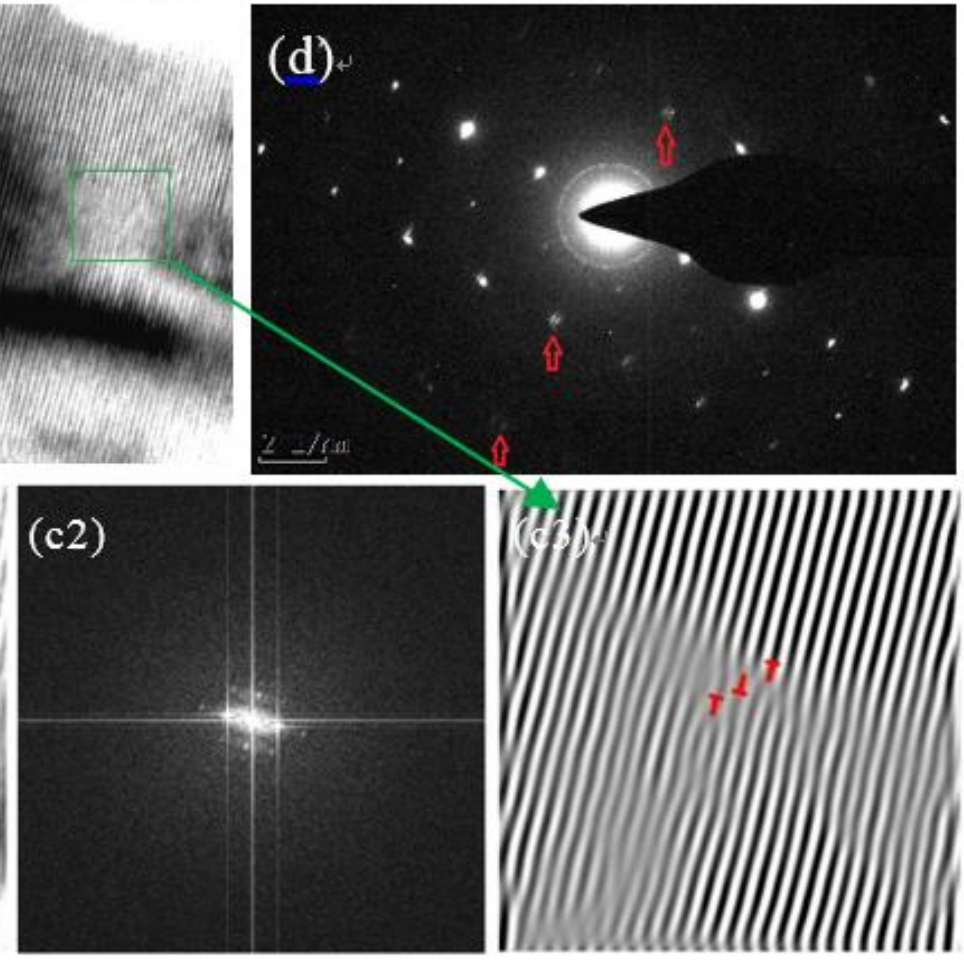

Figure 3 
(a)

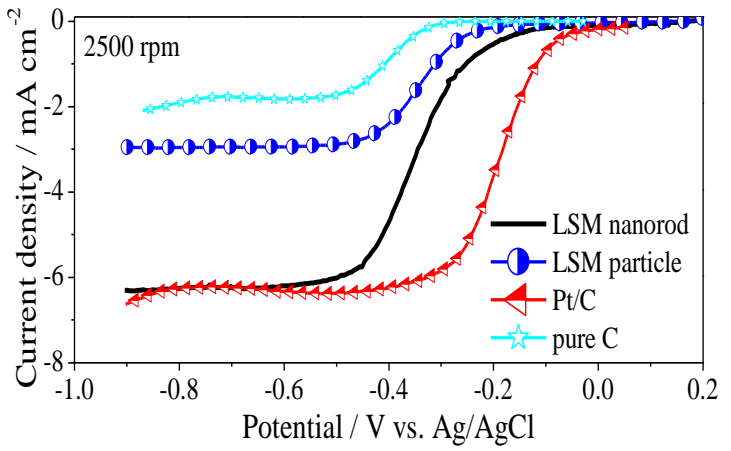

(b)

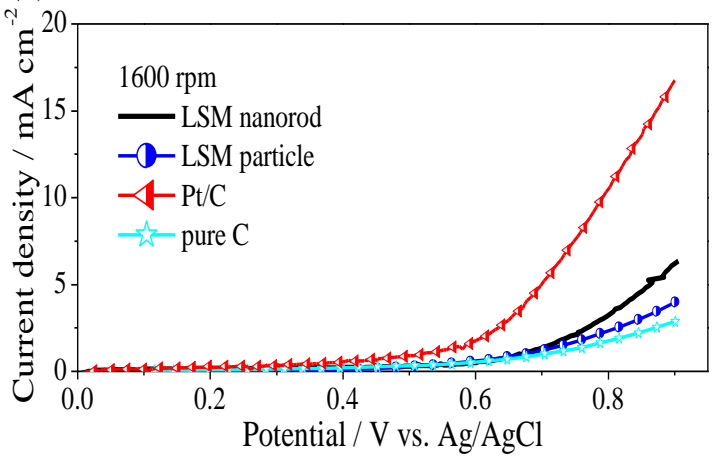

Figure 4 
(a)

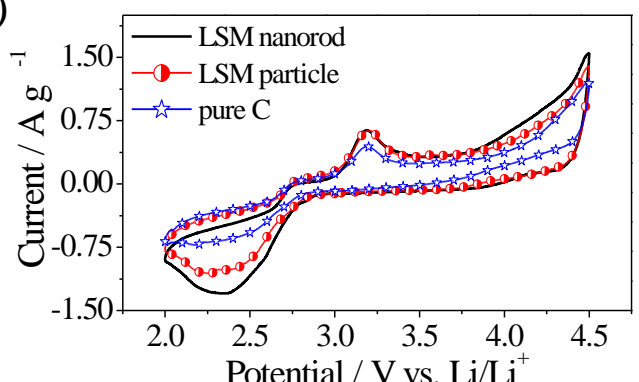

(c)

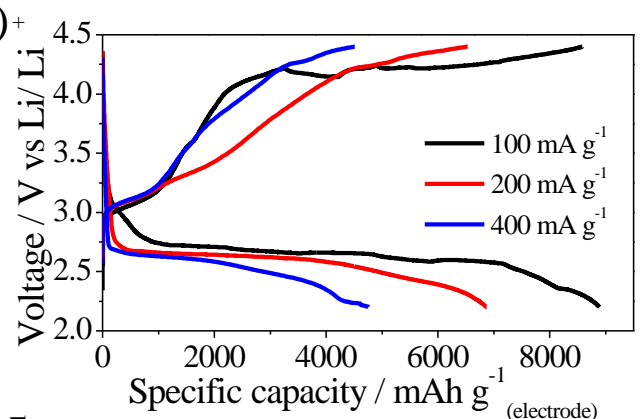

(b)

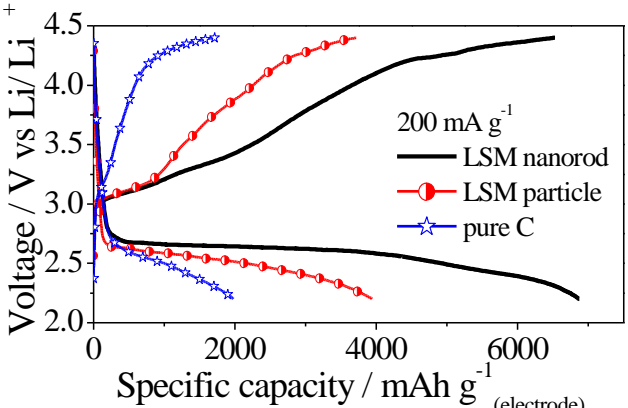

(d)+

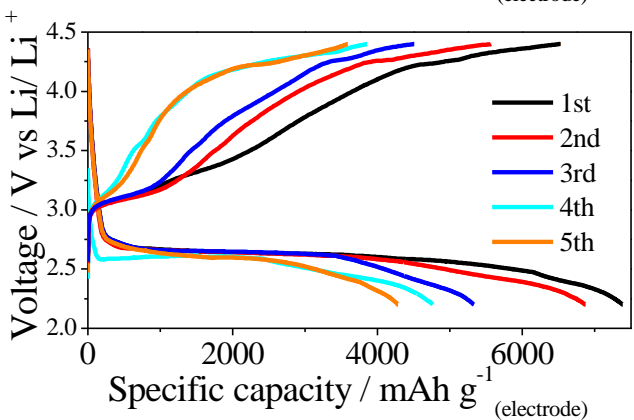

(e)

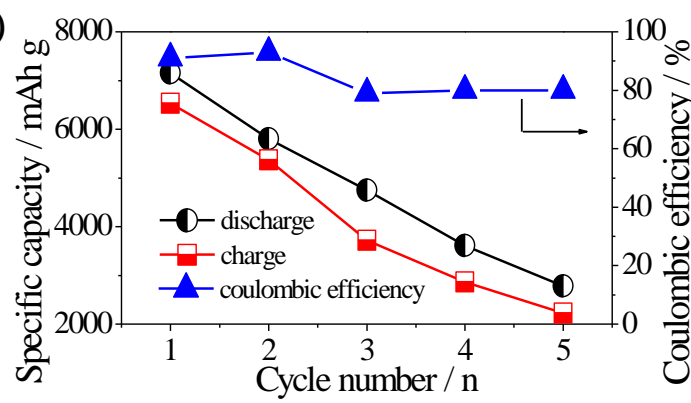

(f)

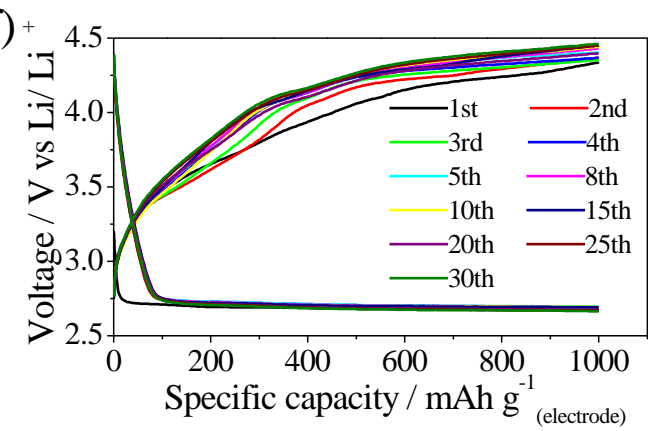

Figure 5 

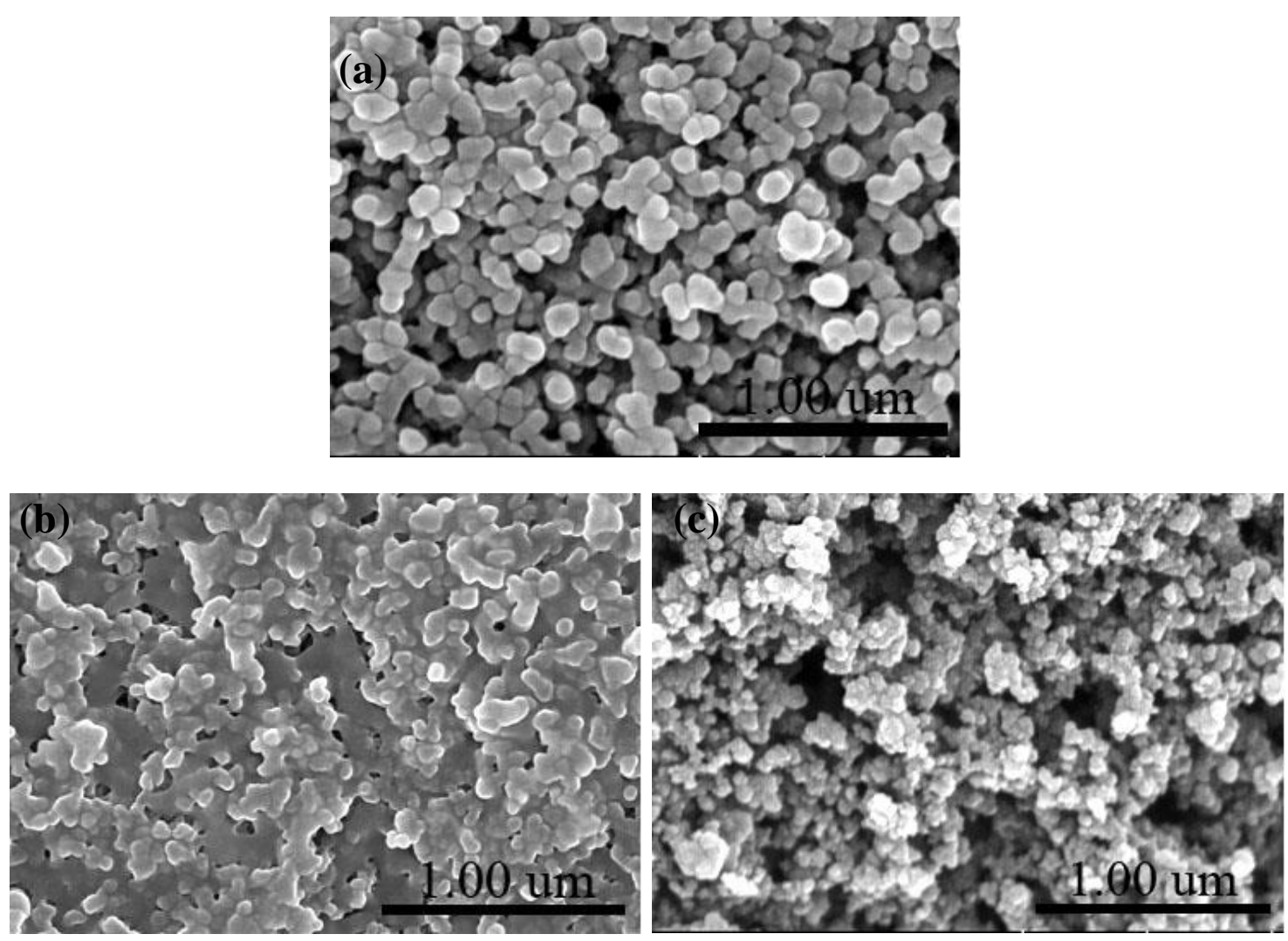

Figure 6 
Tab. 1 Summary of the ORR catalytic characteristics of LSM nanorod, LSM particle, $\mathrm{Pt} / \mathrm{C}$ and pure $\mathrm{C}$.

\begin{tabular}{lccc}
\hline catalyst & $\begin{array}{c}\text { onset potential } \\
(\mathrm{V} \text { vs. Ag/AgCl })\end{array}$ & $\begin{array}{c}\text { half-wave potential } \\
(\mathrm{V} \text { vs. Ag/AgCl })\end{array}$ & $\begin{array}{c}i_{d} \\
\left(\mathrm{~mA} \mathrm{~cm}^{-2}\right)\end{array}$ \\
\hline LSM nanorod & -0.142 & -0.316 & -6.30 \\
LSM particle & -0.191 & -0.338 & -2.95 \\
Pt/C & 0.003 & -0.186 & -6.60 \\
pure C & -0.284 & -0.401 & -1.82 \\
\hline
\end{tabular}

